\title{
A inclusão dos estudantes na academia como um desafio à interculturalidade
}

Inclusion in the academy as a challenge to interculturality

Emília de Carvalho Coutinho ${ }^{1}$, Adriana Pinto Oliveira ${ }^{2}$, Carolina Marques Reis ${ }^{3}$, Inês Raquel Cabral Oliveira ${ }^{4}$, Leonardo de Almeida Maltez ${ }^{5}$, Stefanie Marlene Pereira Osório ${ }^{6}$, Maria Vitória Barros de Castro Parreira ${ }^{7}$, Paula Alexandra de Andrade Batista Nelas ${ }^{8}$, Cláudia Balula Chaves ${ }^{9}$, João Duarte ${ }^{10}$, Sandra Antunes ${ }^{11}$, Paula Marques dos Santos ${ }^{12}$

1 Instituto Politécnico de Viseu, Portugal, E-mail: ecoutinhoessv@gmail.com, ORCID: https://orcid.org/0000-0002-9506-4626

2 Instituto Politécnico de Viseu, Portugal, E-mail: adrianapintoo97@gmail.com, ORCID: https://orcid.org/0000-0002-1526-5867

3 Instituto Politécnico de Viseu, Portugal, E-mail: carolreispfm@gmail.com, ORCID: https://orcid.org/0000-0002-4770-3278

4 Instituto Politécnico de Viseu, Portugal, E-mail: innees96@gmail.com, ORCID: https://orcid.org/0000-0001-7790-1067

5 Instituto Politécnico de Viseu, Portugal, E-mail: maltez.leonardo@gmail.com, ORCID: https://orcid.org/0000-0003-3545-7193

6 Instituto Politécnico de Viseu, Portugal, E-mail: stefanieosorio.97@hotmail.com, ORCID: https://orcid.org/0000-0001-6107-8862

7 Escola Superior de Enfermagem do Porto, Portugal, E-mail: vitoria@esenf.pt, ORCID: https://orcid.org/0000-0002-7962-8057

8 Instituto Politécnico de Viseu, Portugal, E-mail: pnelas@gmail.com, ORCID: https://orcid.org/0000-0003-0043-3597

9 Instituto Politécnico de Viseu, Portugal, E-mail: claudiachaves21@gmail.com, ORCID: https://orcid.org/0000-0002-8103-7221

10 Instituto Politécnico de Viseu, Portugal, E-mail: duarte.johnny@gmail.com, ORCID: https://orcid.org/0000-0001-7082-8012

11 Instituto Politécnico de Viseu, Portugal, E-mail: sandramgantunes@gmail.com, ORCID: https://orcid.org/0000-0002-4626-1543

12 Instituto Politécnico de Viseu, Portugal E-mail: psantos16@gmail.com, ORCID: https://orcid.org/0000-0002-1350-4203

\section{A R T I C LE INFO}

Article history:

Received 2021-04-18

Accepted 2021-05-22

Available online 2021-08-16
Palavras-chave: Vivências. Academia. Exclusão. Interculturalidade. Inclusão.

Keywords: Experiences. Academy. Exclusion. Interculturality. Inclusion. 
RESUMO. A capacidade das Instituições de Ensino Superior (IES) adotarem políticas e dinâmicas promotoras de interculturalidade para a inclusão dos estudantes apresenta-se como um desafio face aos relatos de vivências de exclusão académica dos participantes deste estudo. Foi objetivo deste estudo compreender a experiência vivida pelos participantes, na academia, como fenómeno de inclusão/exclusão. Relativamente aos métodos, trata-se de um estudo qualitativo, fenomenológico-interpretativo, com recurso à entrevista fenomenológica. Participaram trinta e um elementos da comunidade académica (estudantes, docentes e não docentes) de uma IES de Portugal, de abril a julho de 2019. A análise dos dados emergentes foi qualitativa e realizada com ajuda do software Nvivo12. Este estudo insere-se num projeto mais amplo intitulado "Práticas inclusivas no Ensino Superior: O desafio de construir comunidade", autorizado pela Comissão de Ética da Instituição onde se realizou o estudo. Quanto aos Resultados, das categorias emergentes destacamos a Experiência e significado de inclusão, com destaque para a "Indiscriminação", "Igualdade e equidade" e "Integração na comunidade"; as Barreiras à inclusão na instituição, com ênfase nas "Barreiras Arquitetónicas", na "Desarticulação hierárquica institucional, "dificuldades linguísticas" e, ainda, a categoria Sentimentos vivenciados em experiências de exclusão, enfatizados pelos participantes, como a "desvalorização", a "solidão" e a "tristeza". Em conclusão, os participantes consideram que os principais desafios institucionais à inclusão e interculturalidade se centram no derrubar as barreiras arquitetónicas e linguísticas, de forma a que os edifícios tenham acessos adequados à mobilidade, que garantam a sua integração e minimizem sentimentos de desvalorização, solidão e tristeza.

ABSTRACT. The capacity of Higher Education Institutions (HEls) to adopt policies and dynamics that promote interculturality for student inclusion, is a challenge considering the reports, by the participants in this study, of academic exclusion experiences; The aim of this study was to understand the experiences lived in the academy, as inclusion/exclusion phenomena, considering institutional policies and dynamics; Concerning the methods, qualitative, phenomenological-hermeneutic study using phenomenological interviews with thirty one members of the academic community (students, teachers and non-teachers) from a Portuguese HEI, from April to July 2019, supported by qualitative data analysis using Nvivo12. This work is part of a broader project entitled "Inclusive practices in Higher Education: The challenge of building a community", authorized by the Ethics Committee of the Institution involved. In terms of results, the emerging categories were Experience and meaning of inclusion, with emphasis on "Indiscrimination", "Equality and equity" and "Integration into the community"; Barriers to inclusion in the institution, with an emphasis on "Architectural Barriers", "Institutional hierarchical disarticulation" in the adoption of inclusive policies and dynamics and "linguistic difficulties"; and the category Feelings lived in exclusion experiences, with the participants emphasizing "devaluation", "loneliness" and "sadness". In conclusion, participants consider that the main institutional challenges to inclusion and interculturality are focused on breaking down architectural and language barriers, so that buildings have adequate access for all types of mobility, guarantee their integration and minimize feelings of devaluation, loneliness, and sadness. 


\section{Introdução}

A dimensão da exclusão assume-se pela transformação da identidade do indivíduo, inevitavelmente marcada por um sentimento de inutilidade, ligado à sua exclusão social que amplia as dimensões das desigualdades. $O$ tipo de exclusão pode ser económico, político e social RODRIGUES (2020). Apesar deste fenómeno social ser estudado, nomeadamente o impacto social da exclusão de género, cultural, étnico, patológico e religioso (CRUZ, 2018), ainda existem sociedades que não investem na educação, saúde, habitação, segurança e noutros requisitos sociais, que confiram aos indivíduos uma vida condigna. Uma sociedade para ser justa, equilibrada e equitativa tem de promover a integração de todos. Para isso é necessário combater a pobreza, racismo, xenofobia, iliteracia, e outras condições que comprometam a tomada de decisão livre e esclarecida, caso contrário tornarse-á numa sociedade excluidora dos mais vulneráveis, dividida, desordeira, insegura, intransigente, preconceituosa, injusta, fraturante, geradora de segregação e violenta (DIAS SOBRINHO, 2010). Os relatos de vivências de exclusão académica apresentam-se como desafios às Instituições de Ensino Superior (IES) na sua capacidade de desenvolverem, mas também de adotarem políticas promotoras de interculturalidade.

A inclusão em meio académico tem por base uma educação acessível a todos, independentemente das especificidades de cada um. No entanto, promover a adoção de valores e práticas inclusivas, na academia, constitui uma missão complexa e polémica (RODRIGUES, 2018). Complexa - porque na sua génese a escola não foi concebida para todos os estudantes, sendo necessário várias modificações em termos políticos, educacionais e de apoio a projetos de investigação centrados na inclusão. Polémica - porque apesar das recomendações internacionais em termos de Direitos Humanos, são as instituições de ensino que devem reconhecer $e$ atender às especificidades dos estudantes, adequando a sua missão e a sua estrutura em função do respeito pela igualdade, mas também o reconhecimento da diferença e singularidade de cada um. Em 1994, a Organização das Nações Unidas para a Educação, a Ciência e a Cultura (UNESCO) já defendia a inclusão académica, com programas curriculares ajustados (TOMELIN, et al., 2018).

Numa política de qualidade e sucesso, a longo prazo, compete às IES promover e garantir a igualdade de oportunidades e a inclusão social, com corresponsabilização de toda a comunidade académica, assegurando direitos e deveres (GREGERSEN-HERMANS, 2017).

Os estudantes interagem num contexto controlado, com regras e normas, criando um ambiente análogo para todos, apesar de ser culturalmente diverso (COSTA, 2019). Portanto o ensino superior é, ou deveria ser por excelência, um espaço privilegiado para a formação intercultural dos futuros profissionais, num cenário em que se aproximam conceções teóricas e estratégias práticas úteis e eficazes, para fomentar nos estudantes o desejo de conhecer e desenvolver a interculturalidade na sua futura prática profissional, num contexto de inclusão e cidadania (LEIVA e BRACONS, 2019).

Num mundo progressivamente mais global, as sociedades estão cada vez mais plurais decorrente do crescente fluxo de pessoas que atravessam as fronteiras internacionais. DANGIS e LAOYAN (2018) mostram que os estudantes com experiências multiculturais com os seus pares e mentores desenvolveram uma 
consciência cultural e construíram redes sociais. No entanto, referem também experiências negativas, como a discriminação, isolamento social e prática de segregação. Verificaram ainda que os principais fatores dificultadores de inclusão foram as barreiras linguísticas; que para se obterem benefícios da diversidade é importante criar e promover um ambiente inclusivo; e que a interação cultural, estratégias de ensino autêntico, apoio das IES à diversidade e a competência cultural dos docentes são formas de promover a inclusão.

O desafio da educação inclusiva nas IES é alargado ao nível social, educacional e político. Importa a clarificação dos conceitos inclusão e integração, por vezes utilizados como sinónimos, mas que na sua essência divergem. Entendemos que integrar significa formar, coordenar ou combinar, para que não resulte em perda de identidade, ao assumir a identidade da cultura dominante, pela qual se foi assimilado. Incluir significa compreender, fazer parte de ou participar em algo. Consideramos o significado de inclusão aliado ao conceito de participação e como uma necessidade primordial do ser humano. Assim, no contexto académico, o estudante do ensino superior só terá a possibilidade de total desenvolvimento quando incluído num todo, que permita a sua plena participação em todas as áreas da vida académica (SANTOS, et al., 2015).

A Declaração Mundial sobre o Ensino Superior atesta que este deve ser acessível a todos, enquanto direito humano fundamental, pilar da democracia, do desenvolvimento sustentável e da paz (SANTOS et al., 2015). Se por um lado, as IES são o centro do conhecimento, por outro, devem ser o centro da pluralidade, da diversidade e do respeito à diferença (MOREIRA, et al., 2011).

Este trabalho tem, assim, como principal objetivo compreender a experiência vivida pelos participantes na academia, como fenómenos de inclusão ou exclusão.

\section{Metodologia}

Este estudo qualitativo, de cariz fenomenológico-interpretativo, centra-se na experiência vivenciada pelos participantes, na academia, o qual procura dar resposta à seguinte questão de investigação: Que dinâmicas e políticas institucionais são experienciadas como fenómenos de inclusão ou exclusão nas IES?

A metodologia qualitativa procura compreender os fenómenos e apresentálos nos seus variados sentidos (OLIVEIRA, et al., 2017). SPRADLEY (1980) realça esses sentidos na linguagem nativa e na interpretação do investigador. Existe uma estreita relação entre o investigador e o participante pelo que é fundamental compreender a intencionalidade e o significado, compreender os credos, ideias, perceções, representações, perspetivas, conexões, que os participantes atribuem às próprias ações, em interação com os outros e com o ambiente (AMADO, 2014). Em investigação qualitativa, a análise dos dados começa aquando do início com a recolha de dados.

Utilizámos a visão de VAN MANEN (2017) sobre a fenomenologia, como ferramenta particular de observar e perceber a experiência vivida dos participantes. É um método baseado na entrevista compreensiva da vivência do fenómeno (VAN MANEN, 2007). Esta perspetiva de Van Manen, não impõe, o participante fala livremente da sua experiência (PEREIRA, 2015). VAN MANEN (2014) centra-se na ação e interação de cada participante. VAN MANEN (2007) lembra Heidegger que realça o valor formativo da escrita fenomenológica para a reflexão entre o ser e 0 agir, quem somos e como nos comportamos. 
O questionamento filosófico permite compreender o que as pessoas vivem e sentem na interação organizacional. São esses sentidos cognitivos e não cognitivos, a perceção da existência, como refere PEREIRA (2015) sobre o pensamento de Van Manen (2007), que nos ajudam a entender o significado que é atribuído a um determinado fenómeno. Para tal, importa que o investigador faça um corte epistemológico e se torne um "ignorante consciente", abstraindo-se das suas ideias e culturas, para poder captar a experiência vivida pelos participantes tal como ela foi concebida pelos mesmos. O investigador é um observador do mundo, procurando o sentido que os participantes atribuem a cada fenómeno vivido. Neste sentido, a pesquisa fenomenológica tem mais a ver com uma atitude de se posicionar no mundo, do que propriamente com um conjunto de passos a seguir (VAN MANEN, 2014). Foi mais importante captar a experiência humana tal como foi vivida, do que a mera descrição dos factos. O foco de atenção da fenomenologia é a experiência vivida por determinada pessoa, e não a pessoa especificamente que descreve essa experiência, ou o contexto em que se encontra, a fenomenologia não se foca nos factos, mas na experiência humana (VAN MANEN, 2014).

A comunidade académica foi previamente informada da realização do estudo pelos presidentes das unidades orgânicas envolvidas. O presente estudo obedeceu aos critérios éticos das pesquisas com seres humanos, pelo que todo o processo de investigação se iniciou após a explicação, sobre o propósito e os procedimentos, a gravação das entrevistas e a cessação da sua participação a qualquer momento, obtendo o seu consentimento informado livre e esclarecido para a participação no estudo. Previamente o projeto de investigação foi submetido e aprovado pela Comissão de Ética da instituição envolvida.

Dos critérios definidos para a seleção dos participantes, foi considerada a experiência e facilidade em comunicar e expressar os seus sentimentos. Quanto à nacionalidade, $90 \%$ são portugueses e 10\% estrangeiros, nomeadamente, de nacionalidade alemã, angolana e brasileira.

Entre as várias alternativas metodológicas de colheita de dados, optou-se pela entrevista fenomenológica com as questões gerais: Fale-me da sua experiência na academia no domínio da inclusão / exclusão e dos sentimentos vivenciados por si em contextos institucionais que considera terem dificultado a sua inclusão face à interculturalidade.

De forma a responder à questão de investigação formulada, cada participante expressou os seus sentimentos aos acontecimentos e situações vivenciadas, bem como as suas interpretações e o sentido que lhes atribuía. Sentimos que os participantes estavam à vontade, falaram livremente das suas experiências e valorizaram o facto de existir a preocupação em recolher o seu sentir a nível desta problemática. As entrevistas decorreram entre abril e julho de 2019, num gabinete reservado para o efeito e tiveram a duração média de 45 minutos, no entanto, com dois dos participantes docentes, houve necessidade da realização de dois encontros.

Durante a análise seguimos os pressupostos de VAN MANEN (2007, 2014, 2017) para compreender a experiência vivida; em primeiro lugar começámos por selecionar o fenómeno, a perspetiva de estudo, o contexto onde decorreu e os participantes, ou seja, perceber a natureza dessa experiência. Em segundo lugar investigámos essa mesma experiência, que prevê entrar no contexto de estudo, obter as descrições experienciadas e sair do contexto do estudo; em terceiro lugar desenvolvemos uma reflexão fenomenológica hermenêutica; em quarto lugar elaborámos uma escrita fenomenológica hermenêutica; em quinto lugar mantivemos uma relação orientada para o fenómeno; em sexto lugar 
contrabalançámos o contexto da pesquisa (VAN MANEN, 2014). Suportámos a organização dos dados no Nvivo® versão12. Este software permitiu organizar, classificar, ordenar, examinar relações e combinar análises, cruzando dados emergentes da análise, com dados de caracterização dos participantes, entre outras. Neste estudo centrámo-nos na análise do verbatim das entrevistas e, após o tratamento dos dados recolhidos, foi possível identificar dez categorias, cada uma com subcategorias. Pela natureza e tamanho deste artigo apenas foi possível apresentar duas categorias e respetivas subcategorias de análise, nomeadamente "Barreiras à inclusão na instituição" e "Sentimentos vivenciados em experiências de exclusão" as quais estão em total coerência com as questões de investigação formuladas. As categorias foram validadas pelos seis primeiros investigadores apresentados neste artigo, utilizando o software QSR Nvivo 12, inicialmente em processo isolado e, posteriormente, em grupo, tendo-se procedido aos ajustamentos necessários em função do entendimento do todo.

Os testemunhos dos participantes são identificados no texto com letras e números. A primeira letra, letra $\mathrm{E}$, refere-se a dados recolhidos por entrevista. As segundas letras, D, E e N referem-se aos grupos de participantes: (D) docentes, (E) estudantes, e (N) não docentes, respetivamente. Os números representam a ordem pela qual foram realizadas as entrevistas em cada grupo de participantes.

Contribuição dos autores: os primeiros seis autores do presente artigo trabalharam na conceção, execução, análise, interpretação e construção do artigo; os restantes contribuíram na construção do artigo.

Este trabalho é financiado por Fundos Nacionais através da FCT - Fundação para a Ciência e a Tecnologia, I.P., no âmbito do projeto Refํ․ UIDB/00742/2020.

\section{Resultados e discussão}

Foram 30 os participantes no estudo, 10 docentes, 10 não docentes e 10 estudantes (Gráfico 1).

Gráfico 1- Distribuição dos participantes, em função do sexo e ocupação.

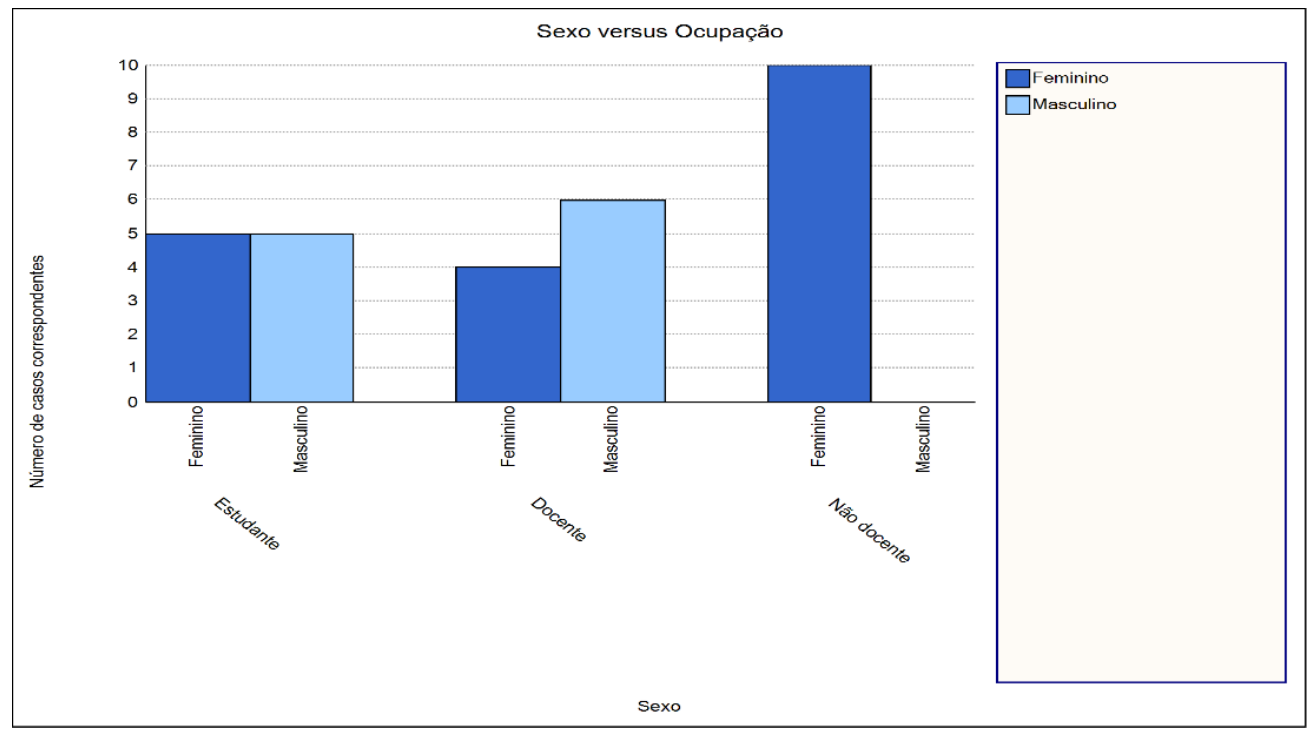

Foram incluídos participantes de todas as faixas etárias (Gráfico 2). 
Gráfico 2 - Distribuição dos participantes em função da faixa etária

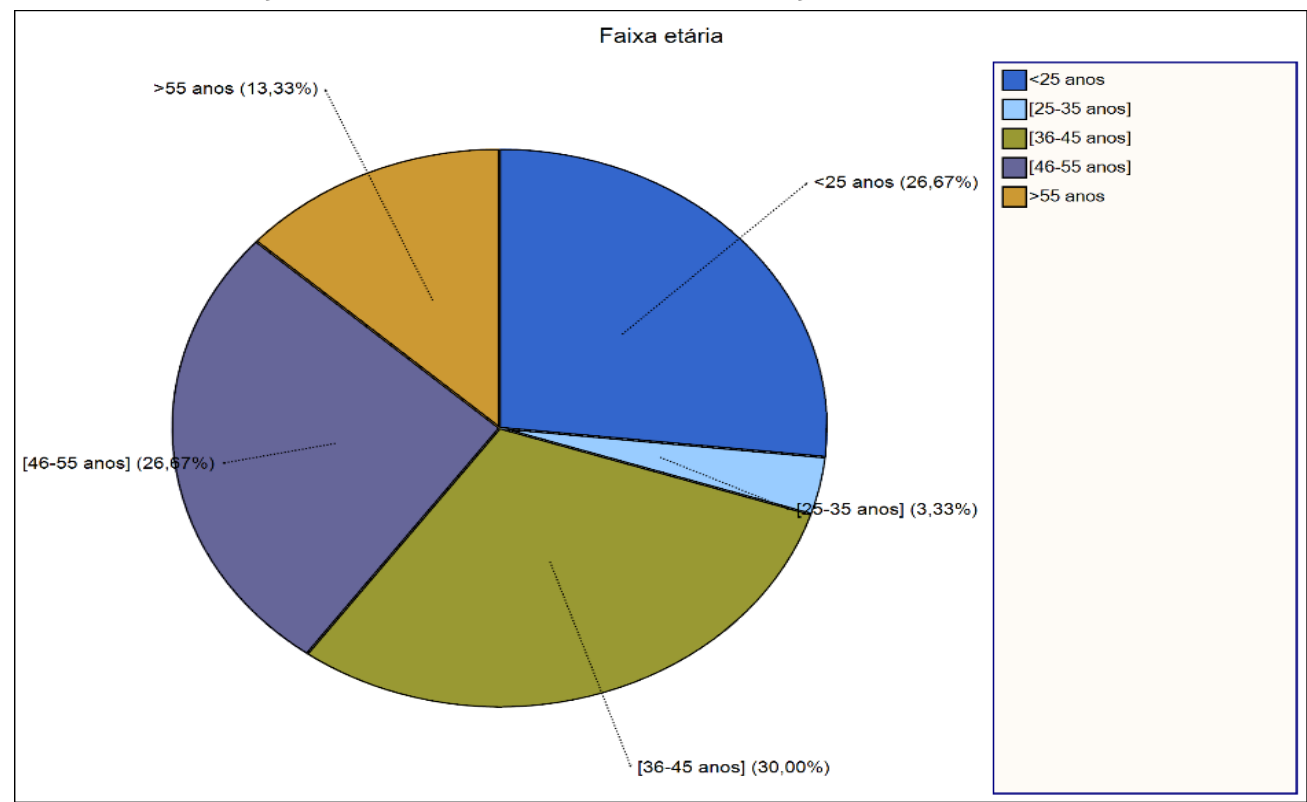

Apresentam-se duas categorias emergentes "Barreiras à inclusão na instituição" e "Sentimentos vivenciados em experiências de exclusão" nas tabelas 1 e 2 , em que n corresponde ao número de participantes e $\mathrm{F}$ ao número de unidades de registo.

\subsection{Experiência e significado de inclusão}

A categoria "Experiência e significado de inclusão" agrega seis subcategorias sendo os fenómenos mais referenciados pelos participantes a "Indiscriminação", "Igualdade e equidade" e "Integração na comunidade". Com menos referências emergiram os significados de "Respeito", "Aceitação" e "Felicidade", conforme tabela 1.

Tabela 1 - Experiência e significado de inclusão

\begin{tabular}{lcc}
\hline Experiência e significado de inclusão & $\mathbf{n}$ & $\mathbf{F}$ \\
\hline Indiscriminação & 12 & 12 \\
Igualdade e equidade & 6 & 7 \\
Integração na comunidade & 4 & 6 \\
Respeito & 4 & 5 \\
Aceitação & 4 & 4 \\
Felicidade & 1 & 2 \\
\hline
\end{tabular}

Indiscriminação - Nesta subcategoria os participantes realçam a não discriminação, aceitação e necessidade de incluir todas as pessoas.

"Não discriminar e incluir todas as pessoas, independentemente do seu género, habilitações literárias, raça, orientação sexual, gostos e preferências, tudo o que define uma pessoa. Basicamente é não 
descartar ninguém exclusivamente por ser diferente ou só por não gostar das mesmas coisas que eu gosto" (EE8)

"É aceitar todos, sem diferenças" (ED1)

"Mesmo pessoas com deficiência, que podem e devem ser integradas na vida dita normal das pessoas, tentando garantir as condições de vida, de trabalho, que essas pessoas necessitam para viver dignamente" (EN5)

"Não ter qualquer tipo de preconceitos em relação a alguém que seja diferente" (ED5)

Respeito - Na subcategoria os participantes enfatizam que este deve ocorrer de forma incondicional.

"Respeito pelo outro independentemente da sua orientação sexual, raça e cultura" (EE5)

"Tolerância e respeito que devemos ter uns pelos outros" (ED1)

"Todos nós temos direitos e deveres que devem ser respeitados" (EN5)

"Não significa nós tentarmos ser iguais ao outro, mas sim termos a nossa identidade, a nossa cultura, os nossos valores, que podem e devem ser respeitados" (EN5)

Igualdade e equidade - A subcategoria emerge dos discursos dos participantes, como sendo enerente à pessoa, independentemente da sua condição.

"Igualdade de oportunidades" (ED9)

"Eu penso que é garantir que há oportunidades iguais, ou pelo menos semelhantes, para pessoas que poderão ter algumas diferenças, algumas dificuldades" (ED2)

"A inclusão é basicamente permitir que todas as pessoas, independentemente de qualquer característica que não seja a mais comum, tenham exatamente as mesmas oportunidades que os outros" (EE11)

"Deixar de pensar mais em nós e pensar mais nos outros" (EE9)

Integração na comunidade - A subcategoria assume o significado de estar incluído, fazer parte, mas também de promover essa inclusão.

"A inclusão significa nós conseguirmos integrar ou integrarmonos em culturas, realidades distintas da nossa" (EN9)

"Inclusão é supostamente para integrar as pessoas na sua diversidade" (ED7)

"Será mais integrar pessoas de fora, mais excluídas" (EE10)

"Integrares-te num grupo de pessoas ou numa sociedade" (EE1)

"Estar incluído, fazer parte" (EN10)

Aceitação - Esta subcategoria está focada na recetividade a novas ideias, valores, conceitos, pessoas, identidades, formas de ver e ser. 
"A inclusão significa (...) sermos aceites e aceitarmos as diferenças, que elas existem" (EN9)

"Aceitar as pessoas que vêm de fora" (EN10)

"É aceitar as pessoas, integrá-las e incluí-las no grupo" (EN7)

"É ter mente aberta, para estar recetiva a novas ideias, novos conceitos, novas pessoas, novas identidades, novas maneiras de ver a vida, as coisas e as pessoas" (EN10)

Felicidade - A felicidade aparece enquanto experiência e significado de inclusão vivenciado.

"Promover o caminho para a felicidade" (ED7)

"Muito feliz" (ED5)

Na categoria "Experiência e significado de inclusão", as subcategorias mais referidas pelos participantes foram "Indiscriminação", "Igualdade e equidade" e "Integração na comunidade". Estas perceções corroboram os princípios da escola inclusiva. RODRIGUES (2018) refere que a inclusão significa ausência de discriminação, pressupõe igualdade de oportunidades e equidade para todos os estudantes. A educação ajuda os estudantes a adquirir a perspetiva de inclusão na sociedade e na aquisição de valores necessários para trabalhar pela igualdade e pela justiça social universal (BANKS, 2008).

Quanto às subcategorias "Respeito", "Aceitação" e "Felicidade" como significado de inclusão experienciado pelos participantes numa IES, há a salientar que também MOREIRA et al., (2011) referem que estes valores são o cerne da pluralidade, da diversidade e do respeito à diferença.

\subsection{Barreiras à inclusão em contexto académico}

A categoria "Barreiras à inclusão em contexto académico" é constituída por dez subcategorias. As mais destacadas foram "Barreiras Arquitetónicas", com dez testemunhos e "Desarticulação hierárquica institucional" com quatro testemunhos, como apresentado na Tabela 1.

Tabela 2 - Barreiras à inclusão em contexto académico

\begin{tabular}{lcc}
\hline Barreiras à inclusão na instituição & $\mathbf{n}$ & $\mathbf{F}$ \\
\hline Barreiras arquitetónicas & 8 & 10 \\
Desarticulação hierárquica & 1 & 4 \\
Dificuldade linguística & 3 & 3 \\
Recursos institucionais escassos & 3 & 3 \\
Turmas e grupo de amigos restrito & 2 & 3 \\
Incapacidade financeira & 2 & 3 \\
Crenças e valores & 1 & 2 \\
Desrespeito pelos lugares reservados a pessoas com & 1 & 2 \\
necessidades específicas & 1 & 2 \\
Pré-requisitos institucionais & 1 & 2 \\
Atividades de praxe humilhantes & & \\
\hline
\end{tabular}

Apresentam-se alguns dos testemunhos reflexivos dos participantes de cada uma das subcategorias.

Barreiras arquitetónicas - Nesta subcategoria os participantes realçam diferentes barreiras arquitetónicas que enfrentam no dia-a-dia entre as quais as 
escadas, rampas, caminhos em terra batida com buracos, às vezes com lama, a ocupação elevada das salas, portas de casa de banho difíceis de abrir, e os próprios edifícios serem afastados uns dos outros, dificultando o acesso a quem tem problemas de mobilidade.

"Temos edifícios afastados uns dos outros e, em alguns locais, há barreiras físicas, como escadas, rampas, caminhos que são em terra, com buracos, às vezes com lama, há essa dificuldade" (ED2) "Temos um estudante que é deficiente motor, em cadeira de rodas e temos algumas dificuldades (...) até em salas que estão com uma ocupação demasiado elevada, às vezes é difícil movimentar-se" (ED2)

"Casas de banho, as portas são difíceis de se abrirem para nós, imagine para pessoas que têm mais dificuldade" (EE2)

"Barreiras físicas por se tratar de um edifício que já tem muitos anos (...) com vicissitudes" (ED8)

Desarticulação hierárquica - A subcategoria revela insatisfação pela falta de envolvimento com os seus superiores e distanciamento entre as diferentes unidades orgânicas.

"Sendo só emanado de cima, torna-se difícil, que cada um conheça aquilo que se passa na instituição" (ED4)

"Proximidade [entre as unidades orgânicas] não está ainda contemplada na instituição" (ED4)

Dificuldade linguística - Esta subcategoria evidencia a falta de conhecimento da língua inglesa por parte da generalidade da comunidade cientifica.

"a principal barreira é a língua (...) há pouca gente a falar inglês. $E$ isso é um problema, quer estudantes, quer professores, quer funcionários, colaboradores" (EN5)

"linguagem... porque a maior parte deste tipo de programas [Erasmus] necessita da língua inglesa (...) há muita dificuldade e a instituição não nos dá ferramentas para ultrapassar esta barreira" (EE9)

Turmas e grupo de amigos restrito - Há quem se lamente pela divisão de estudantes em turmas, referindo que isso acaba por ser uma barreira ao encontro e socialização interpares, levando a que se criem grupos de amigos restritos. Dáse visibilidade a esta problemática com os discursos apresentados.

"Eu sei que é mais fácil o facto de haver duas turmas, mas desta forma, nós não conseguimos incluir tanto a turma $B$, portanto, acho que isso é uma barreia" (EE7)

"[As pessoas] criam os seus próprios grupos e só falam com aquele grupo" (EE4)

Incapacidade financeira - A falta de capacidade financeira é apontada pelos participantes como uma barreira à obtenção de melhores resultados académicos 
levando, por vezes, à perda da bolsa. Alguns discursos exemplificam esta subcategoria.

"Há disciplinas e cursos em que temos que fazer trabalhos e não temos meios. É mais fácil para quem tem dinheiro, comprar o material para aplicar e fazer os projetos. Os professores vão avaliar pelo que está feito e não pelo esforço que tiveram para o fazer. É desagradável quando estamos no ensino público, que se defende tanto, e depois voltamos ao mesmo, em que consoante as possibilidades, assim se dá a nota" (EN7)

"Perder a bolsa por falta de créditos e ter sentido necessidades" (EE10)

"A não atribuição de bolsas a alunos que precisam" (EE10)

Recursos institucionais escassos - A falta de financiamento governamental para recursos específicos por parte das instituições de ensino superior, na aquisição de recursos humanos especializados, condiciona o acesso à educação superior de qualidade por parte de estudantes com necessidades educativas específicas, como expressam alguns testemunhos.

"Por vezes, no ensino não superior há (...) até a nível de acompanhamento mais personalizado [pessoas com necessidades específicas] o que, por vezes, não acontece no ensino superior" (ED6)

"Era importante que a instituição apostasse não só na contratação de professores de língua gestual, como também, na utilização de equipamentos para invisuais e para pessoas com surdez, para acederem a materiais de apoio e acompanhamento das aulas" (ED10)

Crenças e valores - As crenças e valores, como o caso de perspetivas xenófobas, expressos em alguns discursos, realçam a dificuldade de se mudar mentalidades e de se viver a inclusão e interculturalidade.

"Pessoas que têm determinados valores que muitas vezes são difíceis de mudar, tal como perspetivas xenófobas [constituem-se barreiras à inclusão na instituição]" (ED3)

"Algumas crenças vivenciadas como barreiras à inclusão na instituição" (ED10)

Desrespeito pelos lugares reservados a pessoas com necessidades específicas - $\mathrm{O}$ estacionamento indevido em lugares reservado a pessoas com necessidades específicas, é visível em alguns discursos.

"Noto que ainda há pessoas que descriminam essas pessoas [com necessidades específicas] apesar de haver legislação (...)" (EN2) "Estacionarem nos lugares dos deficientes indevidamente" (EN2)

Pré-requisitos institucionais - Os pré-requisitos institucionais são encarados como uma barreira no acesso ao ensino superior por parte de estudantes com necessidades educativas específicas, não revelando igualdade de oportunidades, como revelam alguns testemunhos. 
“... temos uma licenciatura em que adotámos os pré-requisitos e foi algo que foi muito discutido, por vezes, apercebemo-nos que há determinado tipo de formações em que se torna muito mais difícil incluir, ou poder incluir todos (...) porque implica práticas em que há pessoas com alguns tipos de deficiência que ficam impossibilitadas de as realizar" (ED2)

"(...) deve haver oportunidades de igual forma, mas às vezes tem que haver alguma adaptação por parte das pessoas (...) em algumas áreas de formação torna-se mais difícil, especificamente para quem tem determinado tipo de deficiência (...) concordo com inclusão, sim, mas por outro lado, penso que há situações em que não é possível, ou torna-se muito mais difícil de conseguir essa inclusão" (ED2)

Atividades de praxe humilhantes - A praxe é vista como uma barreira à inclusão, na medida em que há exposição e humilhação dos estudantes recémchegados.

"O acolhimento na instituição, ser feito pelos seus praxantes da mesma [é uma barreira à inclusão]" (EE5)

"Tive que me afastar dessa atividade [a praxe]" (EE5)

Relativamente às "Barreiras à inclusão na instituição", destacam-se as subcategorias "Barreiras arquitetónicas" e "Desarticulação hierárquica institucional". As barreiras arquitetónicas, segundo RODRIGUES (2018), nos espaços escolares devem ser anuladas, uma vez que a acessibilidade ao meio físico é fundamental para a inclusão dos estudantes com mobilidade condicionada. Uma das manifestações dessa prática é evidenciado na subcategoria "Desrespeito pelos lugares reservados a pessoas com necessidades específicas".

Como defendem CIANTELLI e LEITE (2016, p. 413), a inclusão de pessoas com deficiência no ensino superior deve ser uma realidade premente, o que pressupõe a anulação de todas as barreiras, incluindo as arquitetónicas.

Uma outra barreira emergente do estudo foi a dificuldade linguística. Também DANGIS e LAOYAN (2018) afirmam que os estudantes estrangeiros tiveram experiências negativas, em contexto semelhante, o que lhes dificultou 0 processo de inclusão. Desta forma, os autores realçam a importância de se ultrapassarem estas barreiras e de promover a diversidade e a competência cultural dos discentes e docentes, como formas de inclusão.

Outras subcategorias emergiram neste estudo como os "Recursos institucionais escassos", "Turmas e grupo de amigos restrito", "Incapacidade financeira", "Crenças e valores", "Pré-requisitos institucionais", e "Atividades de praxe humilhantes". Todas se assumiram como fatores de constrangimento na vida dos participantes. De referir que cabe às IES criar as acessibilidades e assegurar as condições ao pleno desenvolvimento de todos como realçado pela Declaração Mundial sobre o Ensino Superior, que enfatiza o conhecimento como um direito humano fundamental, pilar da democracia, do desenvolvimento sustentável e da paz (SANTOS et al., 2015). 


\subsection{Sentimentos vivenciados em experiências de exclusão}

A categoria "Sentimentos vivenciados em experiências de exclusão" é constituída por oito subcategorias. A subcategoria mais referenciada foi "Desvalorização" com seis unidades de registo e a menos referida foi a subcategoria incapacidade com apenas duas unidades de registo cada, conforme apresentado na Tabela 3.

Tabela 3 - Sentimentos vivenciados em experiências de exclusão

\begin{tabular}{lll}
\hline Sentimentos vivenciados em experiências de exclusão & $\mathbf{n}$ & $\mathbf{F}$ \\
\hline Desvalorização & 3 & 6 \\
Solidão & 3 & 3 \\
Tristeza & 3 & 3 \\
Mal-estar & 2 & 3 \\
Incapacidade & 2 & 2 \\
\hline
\end{tabular}

Apresentam-se algumas unidades de registo que dão corpo às três subcategorias mais referenciadas pelos participantes:

Desvalorização- Nesta subcategoria os participantes realçam a exclusão sentida nos diversos contextos vivenciados. São apresentadas algumas unidades de registo.

\section{"Sinto-me uma carta fora do baralho" (EN3)}

"[O não ser incluída] deixa-me desinserida do meio" (ED3)

"Eu sinto-me muitas vezes desenquadrada, porque realmente são vidas diferentes [pela diferença de idades]" (EE11)

"[O não me incluírem] não me motiva minimamente para eu continuar dentro do trabalho que estou a desenvolver" (ED3)

Solidão - O sentimento de solidão é um reflexo da exclusão vivenciada pelos participantes, mesmo quando estão rodeados de pessoas. São apontados alguns testemunhos.

"[O não ser incluído] é uma sensação muito estranha, uma sensação de estarmos sozinhos quando estamos rodeados de muita gente" (ED3)

"Senti-me um bocado sozinho [por não me adaptar à cidade]" (ED8) "Afasto-me e refugio-me no silêncio (...) quando não tenho [algo] bem para falar, é melhor calar-me" (EN3)

Mal-estar - O mal-estar vivenciado pelos participantes está associado essencialmente a práticas de exclusão na praxe, mesmo por parte de comunidades ditas católicas. Enumeram-se alguns testemunhos.

"Não me senti bem [com a praxe], pelo que me afastei dessa atividade" (EE5)

"E isso dói muito, principalmente porque são comunidades católicas que estão a excluir" (EN3) 
Tristeza - A tristeza é um sentimento vivenciado pelos participantes por não se sentirem incluídos ou não se adaptarem à cidade. São apresentados alguns testemunhos.

"O não ser incluído (...) é algo que para a minha personalidade me deixa triste" (ED3)

"[Senti-me] triste com o que se estava a passar comigo [não me adaptar à cidade]" (EE8)

"É triste [não ser incluída]" (EN3)

Incapacidade - A incapacidade de comunicação e de ajuda dão suporte a esta subcategoria, como expressam alguns testemunhos.

"Eu, por vezes, sinto que podia ter sido mais esclarecedor e ter ajudado mais [na comunicação com colega estrangeiro]" (EE6)

"Sinto que mesmo com o passar do ano ainda há pessoas que estão um pouco de parte e, por mais que eu tente ajudar, acabo por não ter muito sucesso" (EE11)

$\mathrm{Na}$ categoria "Sentimentos vivenciados em experiências de exclusão", o maior destaque pelos participantes foi dado à "Desvalorização". Nesta perspetiva, reforça-se o pressuposto de que os estudantes do ensino superior só terão a possibilidade de um total desenvolvimento quando alcançarem uma plena participação em todas as áreas da vida académica (SANTOS et al., 2015, p. 252), o que implica a adoção de estratégias que levem os estudantes a terem experiências positivas e não de desvalorização, qualquer que seja o contexto. Também DANGIS e LAOYAN (2018) mostram no seu estudo que os estudantes vivenciaram experiências negativas sentindo discriminação, isolamento social e prática da segregação, e que as barreiras linguísticas dificultaram a inclusão; recomendando que para promover a inclusão é importante criar e promover um ambiente inclusivo, em que haja respeito na interação racial, se desenvolvam estratégias de ensino de apoio à diversidade e que a competência cultural dos docentes seja uma realidade. POKER, et al. (2018) vão mais longe dizendo que os próprios docentes reconhecem as suas falhas, bem como o seu défice de formação na área da inclusão, comprometendo a formação e capacitação da comunidade académica no geral a este nível, como também referem COUTINHO et al. (2020).

\section{Conclusões}

O presente estudo de investigação qualitativa permitiu compreender a experiência vivida na academia, cujos sentimentos emergem de vivências de exclusão. Permitiu, também, conhecer as barreiras à inclusão que colocam desafios à instituição no que concerne à inclusão e interculturalidade. Consideraram-se como principais barreiras à inclusão na instituição as barreiras arquitetónicas e a desarticulação hierárquica. Os sentimentos vivenciados como experiências de exclusão, vão desde a desvalorização, à solidão e tristeza. Estes resultados podem constituir um contributo para que a IES utilize este conhecimento como ferramenta de capacitação no desenvolvimento de estratégias e políticas institucionais 
promotoras de dinâmicas e práticas de inclusão e respeito pela interculturalidade, servindo como um ponto de partida para uma futura monitorização do fenómeno de exclusão. Podem ainda incentivar ao desenvolvimento de novas investigações, dinâmicas e políticas nas IES, no sentido de estas se assumirem não apenas como os locais onde se cruzam as pessoas mais habilitadas de um país, mas também como espaços de produção e partilha de conhecimento. Estes resultados permitirão, também, que as IES reflitam na sua missão, nas suas práticas, na essência da sua natureza e na definição e implementação de políticas institucionais que lhes permitam assegurar a inclusão e construir uma comunidade na diversidade e pluralidade, onde se exprima a renovação e a interculturalidade.

\section{Agradecimentos}

Os autores agradecem o apoio da Unidade de Investigação em Ciências da Saúde:Enfermagem (UICISA: E), acolhida pela Escola Superior de Enfermagem de Coimbra (ESEnfC) e financiada pela Fundação para a Ciência e a Tecnologia (FCT). Agradecimentos são devidos igualmente ao Politécnico de Viseu no âmbito da Missão para a Inclusão/Centro Local de Apoio à Integração de Migrantes/SPECULA; e ao Alto Comissariado para as Migrações/Rede de Ensino Superior em Mediação Intercultural/Programa Mentores para Migrantes; SIGMA Tetha Tau- Phi Xi Chapter.

\section{REFERÊNCIAS}

ALVINO-BORBA, A. e MATA-LIMA, H. (2011). Exclusão e inclusão social nas sociedades modernas: Um olhar sobre a situação em Portugal e na União Europeia. Serviço Social e Sociedade: 106: 219-240.

AMADO, J. (coord). (2014). Manual de investigação qualitativa em educação. Imprensa da Universidade de Coimbra. Coimbra.

BANKS, J. (2008). Diversity and citizenship education in global yimes. Em: J. Arthur, I. Davies e C. Hahn (eds.), The Sage handbook of education for citizenship and democracy. Sage. London.

CIANTELLI, A.P.C. e LEITE, L.P. (2016). Ações exercidas pelos núcleos de acessibilidade nas universidades federais brasileiras. Revista Brasileira de Educação Especial. 22: 413-428.

COSTA, D. (2019). Diversidade cultural na universidade em Portugal: Tendências e Desafios. Em: S. GONÇALVES e J.J. COSTA (coords.), Diversidade no ensino superior. CINEP/IPC. Coimbra. Acedido e 10 de novembro de 2020, em: https://www.cinep.ipc.pt/attachments/article/186/-

\%20Diversidade\%20no\%20ensino\%20superior\%202019\%20v23\%20ONLINE+.pdf COUTINHO, E., OLIVEIRA, A.P., REIS, C.M., OLIVEIRA, I.R.C., MALTEZ, L.A., OSÓRIO, S.M.P., PARREIRA, V.P., NELAS, P., CHAVES, C., DUARTE, J., ANTUNES, S., e SANTOS, P. (2020). Vivências de exclusão na academia: Desafios à interculturalidade. New Trends in Qualitative Research. 4: 391-405. Acedido e 10 de novembro de 2020, em: doi:10.36367/ntqr.4.2020.391-405.

CRUZ, N. (2018, 21 de agosto). Exclusão social. Quero Bolsa. São Paulo. Acedido em 10 de novembro de 2020, em: https://querobolsa.com.br/enem/sociologia/exclusao-social DANGIS, G.H., e LAOYAN, M. (2018). The influence of multiculturalism within higher education: Nursing. Degree thesis: Bachelor of health care, Arcada 
University of Applied Sciences, Helsinque. 71 pp. Acedido a 18 de janeiro de 2021, em: https://www.theseus.fi/handle/10024/147763

DIAS SOBRINHO, J. (2010). Democratização, qualidade e crise da educação superior: Faces da exclusão e limites da inclusão. Educação \& Sociedade. 31: 1223-1245. Acedido em 18 de janeiro de 2021, em: http://www.scielo.br/scielo.php?script=sci_arttext\&pid=S010173302010000400010\&nrm=iso

GREGERSEN-HERMANS, J. (2017). Intercultural competence development in higher education. In: D.K. Deardorff, e L.A. Arasaratnam-Smith, A.Intercultural competence in higher education: International approaches, assessment and application. Routledge. London. Acedido em 8 de janeiro de 2021, em: doi:10.4324/9781315529257-7

LEIVA, J. e H. BRACONS (2019). La educación intercultural en la formación inicial del profesorado: La voz de los docentes universitarios. In: A.M. COSTA e SILVA, I. MACEDO e S. CUNHA (eds.), Livro de atas do II Congresso Internacional de Mediação Social: A Europa como espaço de diálogo intercultural e de mediação. CECS. Braga.

MOREIRA, L., BOLSANELLO, M. e SEGER, R. (2011). Ingresso e permanência na Universidade: Alunos com deficiências em foco. Educar em Revista. 41: 125-143. Acedido em 22 de janeiro de 2021, em: http://dx.doi.org/10.1590/S010440602011000300009

OLIVEIRA, E.S.F., BARROS, N.F. e SOUZA, D.C.D.B.N. (2017). Metodologias qualitativas em diferentes cenários: Saúde e educação. Gráfica UFG. Goiânia. PEREIRA, P.S. (2015). Fenomenologia da prática: Investigação em enfermagem da experiência vivida. Revista de Enfermagem UFPE. 9: 9608-9615. Acedido em 10 de novembro de 2020, em: doi:10.5205/reuol.7944-69460-1-SM.0910201525.

POKER, R.B., VALENTIN, F.O.D. e GARLA, I.A. (2018). Inclusão no ensino superior: A percepção de docentes de uma instituição pública do interior do estado de São Paulo. Psicologia Escolar e Educacional. 22: 127-134, 2018. Acedido em 18 de janeiro de 2021, em: http://www.scielo.br/scielo.php?script=sci_arttext\&pid=S1413-

$85572018000400127 \&$ nrm=iso

RODRIGUES, D. (2018, 15 de Abril). Aprofundar a inclusão com o que se sabe. Jornal 0 Publico. Acedido em 10 de novembro de 2020, em: https://www.publico.pt/2018/04/18/sociedade/opiniao/aprofundar-a-inclusao-com-oque-se-sabe-1810760

RODRIGUES, L.O. (2020). Exclusão social. PrePara ENEM. Goiânia (Brasil). Acedido em 10 de novembro de 2020, em: https://alunosonline.uol.com.br/sociologia/exclusao-social.html SANTOS, E., GONÇALVES, M., RAMOS, I., CASTRO, L. e LOEMO, R. (2015). Inclusão no ensino superior: Perceções dos estudantes com necessidades educativas especiais sobre o ingresso à universidade. Revista Portuguesa de Educação. 28: 251-270.

SPRADLEY, J. (1980). Participant observation. Holt Rinehart and Winston. New York.

TOMELIN, K.N., DIAS, A.PL., SANCHEZ, C.N.M, PERES, J. e CARVALHO, S. (2018). Educação inclusiva no ensino superior: Acedido em desafios e experiências de um núcleo de apoio discente e docentes. Revista de Psicopedagogia. 35: 94103, 2018. 
VAN MANEN, M. (2017). But is it phenomenology? Qualitative Health Research. 27: 775-779. Acedido em 10 de novembro de 2020, em: Doi:10.1177/1049732317699570.

VAN MANEN, M. (2007). Phenomenology of practice. Phenomenology \& Practice. 1: 11-30. Acedido em 10 de novembro de 2020, em: http://www.maxvanmanen.com/files/2014/03/Max-Phenomenology-of-Practice1.pdf VAN MANEN, M. (2014). Phenomenology of practice: Meaning giving methods in phenomenological research and writing. Left Coast Press. Walnut Creek, California. 